\title{
CORRESPONDENCE
}

\section{Dangerous severe personality disorder}

Dr Feeney's article (Feeney, 2003) provides a useful review of dangerous severe personality disorder (DSPD). A few minor errors, though, are worth pointing out. Dr Feeney states that 'the PCL-R rates clinical notes and informants with or without interview'. Rating without interview is occasionally employed but it should be noted that, in the words of the instrument's authors, 'the PCL-R is . . . designed to be completed by expert evaluators on the basis of a clinical interview and a review of case history information' (Hart \& Hare, 1996). Dr Feeney also states that those who fulfil the criteria for psychopathy invariably also fulfil the criteria for antisocial personality disorder': this is simply not the case. Lastly, Dr Feeney quotes Professor Gunn's sentiments that the criminal justice system is illequipped to help those with DSPD, but provides no evidence that psychiatrists are any better placed to deal with these problematic individuals.

Feeney, A. (2003) Dangerous severe personality disorder Advances in Psychiatric Treatment, 9, 349-358.

Hart, S. D. \& Hare, R. D. (1996) Psychopathy and antisocial personality disorder. Current Opinion in Psychiatry, 9, 129132.

Andrew Al-Adwani Consultant Psychiatrist, Department of Psychiatry, Scunthorpe District General Hospital, Church Lane, Scunthorpe DN15 1QQ, UK

\section{Author's response}

Assessment for the PCL-R without interview is indeed not standard procedure, but may be done if interview is impossible. Such file-only assessments affect the scoring of interpersonal/affective items, leading to overestimates of low scores and underestimates of high scores (Wong, 1988). The DSM-IV criteria for antisocial personality disorder are based on observable behaviours (irresponsibility and delinquency), whereas the PCL-R considers not only behaviour, but also the interpersonal and affective symptoms (callousness, grandiosity and deceitfulness). There is a subgroup (approximately $10 \%$ ) of those who reach the threshold of 30 on the PCL-R who do not fulfil the DSM-IV antisocial personality criteria on the basis of observed behaviours only. This group is generally made up of 'white collar' criminals (R. Hare, personal communication, 2003). Most Hare psychopaths do meet the criteria for DSM-IV antisocial personality disorder, but most offenders with antisocial personality disorder do not score greater than 30 on the PCL-R (Hare et al, 2000).

Regarding Dr Al-Adwani's third point, I take issue with this use of the acronym DSPD. 'DSPD' does not fulfil the criteria for a diagnostic entity, rather it is the name of a programme. The present interpretation of the treatability clause in the Mental Health Act 1983 has left the psychiatric profession open to criticism that it has abandoned those with severe personality disorder who prove difficult to engage. Arguably this was the basis on which the present DSPD proposals were drawn up. The recent Government guidance proposed that personality disorder should be seen as core work of mental health teams (National Institute for Mental Health in England \& Department of Health, 2003). Adequately resourced, this is an admirable aim. Furthermore, it appears likely that the treatability clause will be omitted in the forthcoming Mental Health Bill. However, psychiatrists should not be involved in the detention of the unconvicted purely on the grounds of perceived risk to the public.

Hare, R., Clark, D., Grann, M., et al (2000) Psychopathy and the predictive validity of the PCL-R: an international perspective. Behavioural Sciences and the Law, 18, 623-645.

National Institute for Mental Health in England \& Department of Health (2003) Personality Disorder: No Longer a Diagnosis of Exclusion. London: Department of Health.

Wong, S. (1988) Is Hare's Psychopathy Checklist reliable without the interview? Psychological Reports, 62, 931-934.

Adrian Feeney Specialist Registrar in Forensic Psychiatry, Fromeside Clinic, Blackberry Hill, Stapleton, Bristol BS16 1ED, UK. Tel: 0117958 3678; fax: 0117958 5477; e-mail: Adrian.Feeney@awp.nhs.uk 